\title{
Duchenne Musküler Distrofi'de hamstring esnekliği ve ambulasyon ilişkili midir?
}

\author{
Are hamstring flexibility and ambulation related in Duchenne Muscular Dystrophy? \\ Lütfiye Akkurt, Güllü Aydın Yağcıoğlu, Numan Bulut, İpek Gürbüz, Aynur Ayşe Karaduman, Öznur \\ Tunca Yılmaz
}

Gönderilme tarihi:06.07.2021

Kabul tarihi:10.11.2021

\section{Öz}

Amaç: Bu çalışmanın amacı Duchenne Musküler Distrofi (DMD)'Ii çocuklarda hamstring esnekliği ile ambulasyon arasındaki iliş̧kiyi araştırmaktır.

Gereç ve yöntem: Çalışmaya yaşları 5 ile 13,5 arasında değişen fonksiyonel seviyeleri Brooke Alt Ekstremite Fonksiyonel Sınıflandırması (BAEFS)'na göre Seviye 1 ve 2 olan 60 DMD tanısı alan çocuk dahil edildi. Çocukların hamstring esnekliği popliteal açı testi, ambulasyonları ise North Star Ambulasyon Değerlendirme (NSAD) skalası ile değerlendirildi. Hamstring esnekliği ve NSAD'nin parametreleri arasındaki ilişki Spearmen korelasyon analizi ile değerlendirildi.

Bulgular: Çalışmaya dahil edilen çocukların hamstring esnekliği ortalamaları $53,78^{\circ} \pm 30,32^{\circ}$ ve $N S A D$ skalası ortalaması ise $24,93 \pm 6,44$ puandı. Hamstring esnekliği ile NSAD skalası arasında negatif yönde, orta kuvvette ilişki bulundu $(r=-0,544, p<0,001)$. NSAD alt parametreleri ile hamstring esnekliği arasındaki ilişkiler incelendiğinde ise esneklik ile birçok alt parametre arasında negatif yönde, zayıf-orta kuvvette anlamlı ilişki bulundu $(p<0,05)$. Ayrıca, BAEFS'na göre Devre 1 ve 2'nin hamstring esnekliği ve NSAD skorunun farklı olduğu bulundu $(p<0,001)$.

Sonuç: Hamstring esnekliğinin DMD'li çocukların ambulasyonu için önemli bir faktör olduğu belirlendi. Hamstring esnekliğini artırıı//koruyucu yaklaşımların erken dönemden itibaren fizyoterapi ve rehabilitasyon programlarında yer almasının bu hasta grubunda ambulasyonun korunması/geliştirilmesi açısından önemli olduğu düşünüldü.

Anahtar kelimeler: Duchenne musküler distrofi, hamstring esnekliği, ambulasyon.

Akkurt L, Aydın Yağcıoğlu G, Bulut N, Gürbüz I, Karaduman AA, Tunca Yılmaz Ö. Duchenne Musküler Distrofi'de hamstring esnekliği ve ambulasyon ilişkili midir? Pam Tıp Derg 2022;15:425-431.

\begin{abstract}
Purpose: The aim of this study was to investigate the relationship between hamstring flexibility and ambulation in children with Duchenne Muscular Dystrophy (DMD).

Materials and methods: Sixty children with a diagnosis of DMD between the ages of 5 and 13,5 and whose functional levels were Level 1 and 2 according to the Brooke Lower Extremity Functional Classification (BLEFC) were included in the study. The hamstring flexibility of the children was evaluated with the popliteal angle test and their ambulation with the North Star Ambulation Assessment (NSAA) scale. The relationship between hamstring flexibility and parameters of NSAA was evaluated with Spearman correlation analysis.

Results: The mean hamstring flexibility of the children included in the study was $53.78^{\circ} \pm 30.32^{\circ}$ and the mean of the NSAA scale was $24.93 \pm 6.44$ points. A negative, moderate correlation was found between the hamstring flexibility and NSAA $(r=-0.544, p<0.001)$. When the relationships between NSAA sub-parameters and hamstring flexibility were examined, a significant relationship was found between flexibility and many sub-parameters in a negative direction, weak-moderate strength $(p<0.05)$. In addition, it was found that hamstring flexibility and NSAA score differ between Levels 1 and 2 according to BLEFC $(p<0.001)$.

Conclusion: Hamstring flexibility was determined to be an important factor for ambulation of children with DMD. Inclusion of hamstring flexibility increasing/protective approaches in physiotherapy and rehabilitation programs from the early period was thought to be important in terms of preserving/developing ambulation in this patient group.
\end{abstract}

Lütfiye Akkurt, Öğr. Gör. Kütahya Sağlık Bilimleri Üniversitesi, Sağlık Bilimleri Fakültesi, Fizyoterapi ve Rehabilitasyon Bölümü, Kütahya, Türkiye, e-posta: lutfiye.akkurt@ksbu.edu.tr (https://orcid.org/0000-0003-3096-513X) (Sorumlu Yazar)

Güllü Aydın Yağcıoğlu, Arş. Gör. Hacettepe Üniversitesi, Fizik Tedavi ve Rehabilitasyon Fakültesi, Ankara, Türkiye, e-posta: gulluaydin23@ gmail.com (https://orcid.org/0000-0003-1658-7697)

Numan Bulut, Arş. Gör. Dr. Fzt. Hacettepe Üniversitesi, Fizik Tedavi ve Rehabilitasyon Fakültesi, Ankara, Türkiye, e-posta: nmn60_90@hotmail. com (https://orcid.org/0000-0001-5427-1103)

İpek Gürbüz, Doç. Dr. Hacettepe Üniversitesi, Fizik Tedavi ve Rehabilitasyon Fakültesi, Ankara, Türkiye, e-posta: ipekalemdaroglu@windowslive. com (https://orcid.org/0000-0001-5556-6608)

Aynur Ayşe Karaduman, Prof. Dr. Lokman Hekim Üniversitesi, Sağlık Bilimleri Fakültesi, Fizyoterapi ve Rehabilitasyon Bölümü, Ankara, Türkiye, e-posta: ayse.karaduman@lokmanhekim.edu.tr (https://orcid.org/0000-0001-6252-1934)

Öznur Tunca Yılmaz, Prof. Dr. Hacettepe Üniversitesi, Fizik Tedavi ve Rehabilitasyon Fakültesi, Ankara, Türkiye, e-posta: oznurtunca@yahoo. com (https://orcid.org/0000-0002-0855-9541) 
Key words: Duchenne muscular dystrophy, hamstring flexibility, ambulation.

Akkurt L, Aydin Yagcioglu G, Bulut N, Gurbuz I, Karaduman AA, Tunca Yilmaz O. Are hamstring flexibility and ambulation related in Duchenne Muscular Dystrophy? Pam Med J 2022;15:425-431.

\section{Giriş}

Duchenne Musküler Distrofi (DMD) çocukluk çağında en sık görülen nöromusküler hastalıktır, insidansı her canlı doğumda 1/3600'dür [1]. Hastalık X kromozomundaki distrofin genindeki herhangi bir mutasyon sonucu oluşur [2]. Ortalama tanı yaşı genellikle semptomların ortaya çıkmaya başladığı 4 yaştır. Hastalığın semptomları ekstremite proksimalinde bilateral kas zayıflığı ile başlar, sonradan ekstremite distali de etkilenir. Ambulasyon kaybı, solunum ve kardiyak problemler zamanla görülür [3].

Ambulasyon, "uygun yardımcı cihazların (protezler, ortezler, bastonlar veya yürüteçler gibi) yardımı ile veya yardımı olmadan, günlük yaşamın mobiliteyle ilgili aktivitelerini güvenli ve yeterli bir şekilde yürütme yeteneği" olarak tanımlanabilir [4]. Ambulasyon skolyoz riski, üst ekstremitenin etkilenmesi, ve yaşam süresini belirleyen ventilasyon desteği ihtiyacı ile ilişkisinden dolayı DMD için önemli bir faktördür [5]. Son yıllarda gelişen tedavi seçenekleri ile uzayan yaşam sürelerine paralel olarak ambulasyonun daha uzun süre devam ettirilmesi ailelerin ve klinisyenlerin en önemli beklentilerindendir. Bu nedenle ambulasyonun devamında etkileyebilecek faktörlerin ortaya konulması gerekmektedir. DMD'de kas kuvveti ve kas kısalıkları gibi faktörlerin ambulasyonu etkilediği bilinmesine rağmen halen farklı parametrelerin ortaya konulmasına intiyaç duyulmaktadır $[6,7]$.

Esneklik ise tam eklem hareket açıklığına ulaşabilme kapasitesidir. Nöromusküler hastalıklarda daha çok kısalıklar üzerinde durulmaktadır [6, 8], ancak esneklik ile özellikle de hamstring ve sırasıyla gastrokinemius, kalça fleksörleri ve TFL esnekliği ile performans arasındaki kuvvetli ilişki önceki çalışmada gösterilmiştir [9]. Literatürde DMD'de esneklik ile performans arasındaki ilişki gösterilmesine rağmen esneklik ile ambulasyon arasındaki ilişkiyi gösteren çalışma bulunmamaktadır. Bu sebeple bu çalışmada öncelikli olarak hamstring esnekliğinin ambulasyon ile ilişkisini ve farklı fonksiyonel seviyelerdeki hastalarda hamstring esnekliğinin nasıl değiştiğini belirlemek amaçlandı.

\section{Gereç ve yöntem}

Brooke Alt Ekstremite Fonksiyonel Skalası'na (BAEFS) göre Devre 1 ve 2 olan 60 DMD'li çocuk çalışmaya dahil edildi. Çalışma; Hacettepe Üniversitesi, Fizik Tedavi ve Rehabilitasyon Fakültesi, Nöromusküler Hastalıklar Ünitesi'nde gerçekleştirildi.

Dahil edilme kriterleri:

\section{- Duchenne Musküler Distrofi tanısı} almak

- Fonksiyonel seviyesi BAEFS'e göre Devre 1 ve 2 olmak

- Mental ve kognitif problemi olmamak

- Son 6 ay içinde ortopedik cerrahi geçirmemiş olmak

Dahil edilme kriterlerini sağlamayan ve çalışmaya katılmayı kabul etmeyen çocuklar çalışma dışı bırakıldı.

Çocuklar ve ebeveynleri çalışmaya katılmak için bilgilendirilmiş onam formlarını imzaladılar. Çalışma, Hacettepe Üniversitesi Girişimsel Olmayan Klinik Araştırmalar Etik Kurulu tarafından onaylandı.

\section{Brooke Alt Ekstremite Fonksiyonel Skalası}

(BAEFS): BAEFS çocukların fonksiyonel seviyelerini değerlendirmek için kullanılır. Skala, Devre 1 (bağımsız yürüyen ve merdiven çıkabilen) ile Devre 10 (yatağa bağımlı) arasında değişen 10 devreden oluşur [10, 11].

Hamstring esnekliğinin değerlendirilmesi: Hamstring esnekliğini değerlendirmek için popliteal açı testi kullanıldı. Popliteal açı testi aktif diz ekstansiyonunu içeren bir testtir. Test iki fizyoterapist ile yapıldı. Test sırasında çocuk yatağa sırtüstü yatar ve birinci fizyoterapist tarafından kalça $90^{\circ}$ fleksiyonda pozisyonlanır. Çocuktan aktif olarak alt bacağını ekstansiyona getirmesi istenir. Ikinci fizyoterapist açıyı ölçmek için gonyometre kullanır. Dizin tam ekstansiyonundan eksik olan açı "popliteal açı" olarak kaydedildi. Diğer kalça ve diz ekstansiyon pozisyonundaydı. Ölçümler üç tekrarlı yapıldı ve en yüksek değer derece 
olarak kaydedildi $[12,13]$. Hem sol hem de sağ hamstring esnekliği ölçüldü. Sol ve sağ ölçümlerin ortalaması hesaplandı ve sağ-sol ortalama olarak kaydedildi.

North Star Ambulasyon Değerlendirmesi: North Star Ambulasyon Değerlendirme (NSAD) skalası 5 yaş ve üzeri ambule DMD'li çocukların ambulasyonunu değerlendirmek için kullanılan temel klinik değerlendirmelerdendir [14]. NSAD, DMD için yüksek geçerliliği ve güvenirliği olan fonksiyonel bir skaladır. Skala sırtüstü yatmadan koşmaya kadar ambulasyonun her seviyesini değerlendiren 17 bölümden oluşur, bu yönüyle DMD için geçerli bir skaladır [1518]. Skalada her bölüm $0-2$ arasında puanlanır ve total skor 0-34 arasındadır. Ayrıca, skala performansı değerlendiren Gowers ve $10 \mathrm{~m}$ koşma bölümlerini içerir [19]. Ayrıca skalanın bazı maddeleri çıkartılarak 3 yaş ve üzeri DMD'li çocuklarda kullanılabilen revize versiyonu da yapılmıştır [17].

\section{İstatiksel analiz}

İstatiksel analiz için SPSS 21.0 versiyonu (SPSS Inc. Chicago, IL, USA) kullanıldı. Tanımlayıcı analizler minimum, maksimum ve ortalama \pm standart sapma $(X \pm S S)$ olarak verildi. Verilerin normal dağılıma uygunluğu SkewnessKurtosis testi, histogram analizi, KolmogorovSmirnov testi ve varyasyon katsayısı ile değerlendirildi. Istatistiksel analizde veriler arasındaki ilişkiye bakılırken verilerin her ikisi de normal dağılım gösterdiğinde Pearson Correlation katsayısı ( $r$ ), verilerden en az bir tanesi bile normal dağılım göstermediğinde ise Spearman Correlation katsayısı (r) kullanıldı. Veriler normal dağıım göstermediği için ilişkiyi değerlendirmek için Spearman korelasyon katsayısı (r) kullanıldı. Korelasyon kuvveti sırasıyla çok kuvvetli $=0,90-1,00$, kuvvetli $=0,70-0,89, \quad$ orta $=0,40-0,69$, zayıf $=0,10-0,39$ ve önemsiz=0,00-0,10. Mann-Whitney $U$ testi iki grup arasındaki farkı değerlendirmek için kullanıldı. İstatiksel anlamlılık değeri için $p<0,05$ kabul edildi [20]. Örneklem büyüklüğü hesaplanmasında G*Power kullanılmıştır ve değerlendirilen ilk 30 hasta ile priori güç analizi yaptırılarak $\% 80$ güç ve $\% 5$ tip 1 hata düzeyi ile 60 hastanın çalışmaya dahil edilmesinin gerekli olduğu sonucuna varılmıştır [21].

\section{Bulgular}

Çalışmaya toplamda 60 çocuk dahil edildi. Çocuklardan 30'unun fonksiyonel seviyesi Devre 1 iken diğer yarısının Devre 2 olduğu belirlendi. Çocukların demografik özellikleri Tablo 1'de verildi.

Çocukların hamstring esnekliği 53,78 $\pm 30,32$ derece ve NSAD total skoru $24,93 \pm 6,43$ idi. Devre 1 ve 2'deki çocukların hamstring esnekliği ve total NSAD skorlarının karşılaştııııması Tablo 2'de gösterildi. Devre 1 ve 2 arasında NSAD ve hamstring esnekliği açısından istatistiksel

Tablo 1. Çocukların demografik özellikleri $(n=60)$

\begin{tabular}{|c|c|c|c|c|c|}
\hline & $\begin{array}{l}\text { Brooke } 1(n=30) \\
\text { Ortalama } \pm S S\end{array}$ & $\begin{array}{l}\text { Brooke } 2(n=30) \\
\text { Ortalama } \pm S S\end{array}$ & $\begin{array}{l}\text { Brooke } 1 \text { ve } 2 \\
(n=60) \\
\text { Min-Maks }\end{array}$ & $\begin{array}{l}\text { Brooke } 1 \text { ve } 2 \\
(n=60) \\
\text { Ortalama } \pm S S\end{array}$ & $p$ \\
\hline Yaş (yıl) & $6,9 \pm 1,29$ & $8,99 \pm 1,64$ & $5-13,5$ & $7,94 \pm 1,8$ & $<0,001$ \\
\hline Boy (cm) & $117,6 \pm 9,64$ & $125,77 \pm 9,21$ & $102-148$ & $121,68 \pm 10,21$ & 0,001 \\
\hline Vücut ağırlığı (kg) & $23,4 \pm 6,59$ & $28,76 \pm 8$ & $15-55$ & $26,08 \pm 7,75$ & 0,002 \\
\hline
\end{tabular}

$\mathrm{cm}$ : santimetre, kg: kilogram, SS: Standart Sapma

Tablo 2. Gruplar arasında total NSAD skoru ve hamstring esnekliğinin karşılaştıııması $(n=60)$

\begin{tabular}{|c|c|c|c|c|}
\hline & $\begin{array}{l}\text { Brooke } 1(n=30) \\
\text { Ortalama } \pm S S\end{array}$ & $\begin{array}{l}\text { Brooke } 2(n=30) \\
\text { Ortalama } \pm S S\end{array}$ & $\mathbf{z}$ & $p$ \\
\hline NSAD (0-34) & $29,93 \pm 3,42$ & $19,93 \pm 4,57$ & $-0,6$ & $<0,001^{* *}$ \\
\hline $\begin{array}{l}\text { Hamstring esnekliği } \\
\text { (sağ-sol ortalama) }\left({ }^{\circ}\right)\end{array}$ & $34,7 \pm 13,4$ & $72,86 \pm 30,61$ & $-4,65$ & $<0,001^{* *}$ \\
\hline
\end{tabular}

NSAD: North Star Ambulasyon Değerlendirmesi, SS: Standart Sapma, ${ }^{*} p<0,05,{ }^{* *} p<0,01$ 
olarak anlamlı bir farklılık bulundu $(p<0,001)$. Hamstring esnekliği ve NSAD toplam skoru ve alt parametreleri arasındaki ilişki Tablo 3'te gösterildi. Sonuçlara göre, hamstring esnekliği ile NSAD toplam skoru arasında orta kuvvette, negatif yönde, istatistiksel olarak anlamlı ilişki bulundu. Hamstring esnekliği ve NSAD alt parametrelerinden yürüme, sandalyeden kalkma, sağ/sol ayakla basamak çıkma, sağ/sol ayakla basamak inme, yerden kalkma, topuklar üzerinde durma, zıplama, sağ/sol ayak üzerinde zıplama, koşma arasında zayıf-orta kuvvette, negatif yönde, istatistiksel olarak anlamlı ilişki tespit edildi $(p<0,05, p<0,01)$.

Tablo 3. Hamstring esnekliği ile NSAD parametreleri arasındaki ilişki $(n=60)$

\begin{tabular}{|c|c|c|}
\hline & \multicolumn{2}{|c|}{ Hamstring esnekliği (sağ-sol ortalama) } \\
\hline & $\mathbf{r}$ & $p$ \\
\hline 1. Ayakta durma & $-0,232$ & 0,075 \\
\hline 2. Yürüme & $-0,369$ & $0,004^{* *}$ \\
\hline 3. Sandalyeden kalkma & $-0,351$ & $0,006^{* *}$ \\
\hline 4. Sağ ayak üzerinde durma & $-0,106$ & 0,418 \\
\hline 5. Sol ayak üzerinde durma & $-0,035$ & 0,790 \\
\hline 6. Sağ ayakla basamak çıkma & $-0,533$ & $<0,001^{* *}$ \\
\hline 7. Sol ayakla basamak çıkma & $-0,613$ & $<0,001^{* *}$ \\
\hline 8. Sağ ayakla basamak inme & $-0,404$ & $0,001^{* *}$ \\
\hline 9. Sol ayakla basamak inme & $-0,278$ & $0,032^{*}$ \\
\hline 10. Oturmaya gelme & $-0,017$ & 0,898 \\
\hline 11. Yerden kalkma & $-0,329$ & $0,01^{*}$ \\
\hline 12. Başını kaldırma & $-0,017$ & 0,9 \\
\hline 13. Topuklar üzerinde durma & $-0,436$ & $<0,001^{* *}$ \\
\hline 14. Zıplama & $-0,520$ & $<0,001^{\star *}$ \\
\hline 15. Sağ ayak üzerinde zıplama & $-0,416$ & $0,001^{* *}$ \\
\hline 16. Sol ayak üzerinde zıplama & $-0,430$ & $0,001^{* *}$ \\
\hline 17. Koşma $(10 \mathrm{~m})$ & $-0,390$ & $0,002^{* *}$ \\
\hline NSAD total skoru & $-0,544$ & $<0,001^{* *}$ \\
\hline
\end{tabular}

NSAD: North Star Ambulasyon Değerlendirmesi, ${ }^{*} p<0,05,{ }^{* *} p<0,01$

\section{Tartışma}

DMD’li çocuklarda hamstring esnekliği ile ambulasyon arasındaki ilişkinin incelendiği bu çalışmada erken dönem DMD'li çocuklarda hamstring esnekliğinin ambulasyon ile ilişkili olduğu bulundu. Hamstring esnekliğinin NSAD skalasının parametrelerinden sadece ayakta durma, oturmaya gelme ve başını kaldırma gibi hamstring kas aktivitesine öncelikli intiyaç olmayan aktiviteler dışında 17 maddeden 12 'si ile ilişkili olduğunun bulunması bu kasın esnekliğinin korunmasının ambulasyon için önemini ortaya koymuştur.

DMD'de ambulasyon kaybı ilerleyici kas zayıflıkları ve bu duruma sekonder gelişen problemler sonucunda oluşmaktadır. Ambulasyon kaybı hastaların bağımsızlığının azalması ve dolayısıyla günlük yaşam aktivitelerinde bakım verene bağımlıı̆̆ını artırdığı için hastalar ve aileleri için önemli fiziksel ve psikolojik etkileri olan bir durumdur [22]. Bu sebeple DMD'li çocuklarda ambulasyonun değerlendirildiği bu çalışmada fonksiyonel seviye kötüleştikçe NSAD skalasına göre ambulasyonda yaklaşık 10 puanlık bir kaybın olduğu raporlandı. Bu sonuçların literatürdeki hastalığın doğal seyri üzerine yapılan çalışmalarla uyumlu olduğu gözlendi. Ancak ambulasyondaki ciddi kayıpların kas zayıflığının artış gösterdiği, postüral değişikliklerin daha net izlendiği daha ileri devrelerde olması 
beklenirken bu iki devre arasındaki \%33'lük düşüş dikkat çekicidir. Hastalığın en erken devresinde ambulasyon puanındaki bu ciddi düşüş yapılacak tüm tedavi yaklaşımları ve fizyoterapi uygulamalarının erken devredeki önemini ve uzun vadede ambulasyon süresinin uzamasında etkili olabileceğini düşündürdü.

Pediatrik hastalık gruplarında ambulasyonu değerlendirmenin yanı sıra ambulasyonu etkileyen faktörlerin belirlenmesi de bir o kadar önemlidir. Hamstring esnekliğinin performans üzerine etkisi serebral palsi, generalize eklem hipermobilitesi olan çocuklar, sporcular gibi birçok popülasyonda gösterilmiştir. Serebral palside esnekliğin sıralama performansı üzerinde etkisi olduğu bulunmuştur [23]. Generalize eklem hipermobilitesi olan çocuklarda ise hamstring esnekliğinin çeviklik ve dikey sıçrama performansını artırdığı bulunmuştur [24]. Sporcularda yapılan bir çalışmada ise daha az hamstring esnekliği olan sporcuların \%30 daha fazla yaralanma riskine sahip olduğu ve performanslarının daha düşük olduğu bulunmuştur [25]. DMD'de de hamstring esnekliğinin fonksiyonel performans üzerine etkisi araştırılmış ve önemli ölçüde etkilediği bildirilmiştir [9].

DMD'de kas kısalıkları ve kas kuvveti gibi parametrelerin hastalığın ilerleyici özelliği nedeni ile ileri devrelerde olumsuz etkilendiği bilinmesine rağmen bu hastalarda esnekliğin değişimi ile ilgili bilgiler limitlidir. Çalışmamızda DMD'li çocuklarda Devre 1 ve 2 arasında yaklaşık hamstring esneklik kaybının 2 kat artış gösterdiği belirlendi. DMD için erken devre olarak kabul edilen ve henüz fonksiyonel kayıpların belirgin olmadığı bu dönemde hamstring esnekliğindeki bu önemli değişimi klinisyenler için ambulasyonu etkileyen önemli bir parametre olarak değerlendirilmiştir. Bu nedenle DMD'de esnekliğin ve özellikle de hamstring esnekliğinin erken dönemlerden itibaren değerlendirilmesi ve tedavi edilmesinin önemli olduğu düşünülmüştür.

DMD'de ambulasyonu etkileyen birçok faktör olduğu bilinmekle birlikte esnekliğin ambulasyona etkisi ile ilgili bir çalışmaya rastlanmamıştır [6, 8, 26]. DMD'lilerde yapılan bir çalışmada, kalça fleksiyonu, diz fleksiyonu ve ayak bileği plantar fleksiyon kontraktürünün yaygın olduğu ve non-ambulatuar çocuklarda kontraktürlerin daha ciddi olduğu bulunmuştur. Erken ambulatuar dönemde ayak bileği plantar fleksiyon kontraktürü sıklıkla oluşmakla birlikte, sırasıyla kalça ve diz eklem kontraktürlerinin görüldüğü bildirilmiştir [26]. Kiefer ve ark. [6] DMD'li hastalarda plantar fleksör kontraktürü ve NSAD arasındaki ilişkiyi araştırmışlar ve her yıl ayak bileği kontraktürünün 1,43 derece arttığını, NSAD'nin ise 1,86 puan azaldığını bulmuşlardır. Bu çalışmada ayak bileği kontraktürünün NSAD için prediktif bir faktör olduğu bildirilmiştir. Hamstring esnekliği ve NSAD arasındaki ilişki ele alındığında, esnekliğin NSAD için prediktif bir faktör olabileceği, ancak bunun için daha fazla sayıda hastanın dahil olduğu çalışmalara intiyaç duyulmaktadır.

Çalışmamızın en önemli kısıtlılığı örneklemin sadece Devre 1 ve 2 olan DMD'li çocuklardan oluşmasıdır. Ancak DMD'de Devre 3 ve sonrası çocuklarda ciddi kas kuvvet kayıpları oluştuğu için bu devredeki çocuklara aktif diz ekstansiyonunu içeren popliteal açı testi uygulanamamaktadır. Bu yüzden ileri devredeki çocuklarda bu testin varsa modifiye şekilleri yada başka hamstring esneklik testleri kullanılabilir. Diğer bir kısıtlılık ise sadece hamstring esnekliği değil diğer alt ekstremite kaslarınında esnekliği değerlendirilmesinin gerekli olduğunu düşünmekteyiz.

Sonuç olarak, bu çalışmada erken devredeki DMD'de yaşın ilerleyişi ve fonksiyonel seviyedeki düşüş ile hamstring esnekliğinin azaldığı ve bunun ambulasyonu olumsuz etkilediği belirlendi. DMD'de çok erken dönemde Devre 1 ve 2 arasında belirlenen hamstring kas esnekliğinde ve ambulasyon puanındaki azalma değerlendirme ve tedavi programının planlanmasında önemli bir yol göstericidir. Bu sonuçlar DMD'de erken dönemden itibaren kas esnekliğinin korunmasının hastalığın tedavisindeki başarıyı arttırabileceği ve uzun dönemde ambulasyon süresine katkıda bulunabileceğini düşündürmüştür. Çalışmamızın hastalığın erken devrelerindeki çocuklarla yapılması ilerleyen devrelerde hamstring kısalığının etkisini göstermesi açısından önemli olabileceğinden sonraki çalışmalarda ambulatur dönemin son devrelerindeki çocukların katıldığı ve diğer alt ekstremite kasları ve gövde kaslarının esnekliğinin ambulasyon parametrelerine etkisinin araştırıldığı çalışmalara ihtiyaç duyulmaktadır.

Çıkar ilişkisi: Yazarlar çıkar ilişkisi olmadığını beyan eder. 


\section{Kaynaklar}

1. Chung J, Smith AL, Hughes SC, et al. Twenty-year follow-up of newborn screening for patients with muscular dystrophy. Muscle Nerve, 2016;53:570-578. https://doi.org/10.1002/mus.24880

2. Pane, M, Scalise $R$, Berardinelli $A$, et al. Early neurodevelopmental assessment in duchenne muscular dystrophy. Neuromuscul Disord 2013;23:451455. https://doi.org/10.1016/j.nmd.2013.02.012

3. Parreira SLS, Resende MBD, Zanoteli E, Carvalho MS, Marie SK, Reed UC, Comparison of motor strength and function in patients with duchenne muscular dystrophy with or without steroid therapy. Arq Neuro-Psiquiatr 2010;68:683-688. https://doi.org/10.1590/s0004282x2010000500002

4. Lam T, Noonan VK, Eng JJ. A systematic review of functional ambulation outcome measures in spinal cord injury. Spinal Cord 2008;46:246-254. https://doi. org/10.1038/sj.sc.3102134

5. Landfeldt E, Sejersen T, Tulinius M. A mini-review and implementation model for using ataluren to treat nonsense mutation duchenne muscular dystrophy. Acta Paediatr 2019;108:224-230. https://doi.org/10.1111/ apa.14568

6. Kiefer M, Bonarrigo K, Quatman Yates K, Fowler A, Horn PS, Wong BL. Progression of ankle plantarflexion contractures and functional decline in duchenne muscular dystrophy: implications for physical therapy management. Pediatr Phys Ther 2019;31:6166. https://doi.org/10.1097/PEP.0000000000000553

7. Lerario A, Bonfiglio S, Sormani MP, et al. Quantitative muscle strength assessment in duchenne muscular dystrophy: longitudinal study and correlation with functional measures. BMC Neurol 2012;12:91. https:// doi.org/10.1186/1471-2377-12-91

8. Case LE, Apkon SD, Eagle M, et al. Rehabilitation management of the patient with duchenne muscular dystrophy. Pediatrics 2018;142:17-33. https://doi. org/10.1542/peds.2018-0333D

9. Akkurt L, Alemdaroğlu Gürbüz İ, Karaduman A, Tunca Yilmaz Ö. Lower limb flexibility in children with duchenne muscular dystrophy: effects on functional performance. Pediatr Exerc Sci 2019;31:42-46. https:// doi.org/10.1123/pes.2018-0115

10. Akima H, Lott $D$, Senesac $C$, et al. Relationships of thigh muscle contractile and non-contractile tissue with function, strength, and age in boys with duchenne muscular dystrophy. Neuromuscul Disord 2012;22:1625. https://doi.org/10.1016/j.nmd.2011.06.750

11. Brooke MH, Griggs RC, Mendell JR, Fenichel GM, Shumate JB, Pellegrino RJ. Clinical trial in duchenne dystrophy. I. The design of the protocol. Muscle Nerve 1981;4:186-197. https://doi.org/10.1002/ mus. 880040304
12. Winslow J. Treatment of lateral knee pain using soft tissue mobilization in four female triathletes. Int $\mathrm{J}$ Ther Massage Bodywork 2014;7:25-31.

13. Czaprowski D, Leszczewska J, Kolwicz A, et al. The comparison of the effects of three physiotherapy techniques on hamstring flexibility in children: a prospective, randomized, single-blind study. PloS One 2013;8:e72026. https://doi.org/10.1371/journal. pone.0072026

14. Birnkrant DJ, Bushby K, Bann CM, et al. Diagnosis and management of duchenne muscular dystrophy, part 1: diagnosis, and neuromuscular, rehabilitation, endocrine, and gastrointestinal and nutritional management. Lancet Neurol 2018;17:251-267. https:// doi.org/10.1016/S1474-4422(18)30024-3

15. De Sanctis R, Pane M, Sivo $S$, et al. Suitability of north star ambulatory assessment in young boys with duchenne muscular dystrophy. Neuromuscul Disord 2015;25:14-18. https://doi.org/10.1016/j. nmd.2014.09.015

16. Pane M, Mazzone ES, Sivo S, et al. Long term natural history data in ambulant boys with duchenne muscular dystrophy: 36-month changes. PloS One 2014;9:e108205. https://doi.org/10.1371/journal. pone. 0108205

17. Mercuri E, Coratti G, Messina S, et al. Revised north star ambulatory assessment for young boys with duchenne muscular dystrophy. PloS One 2016;11:e0160195. https://doi.org/10.1371/journal.pone.0160195

18. Mazzone E, Martinelli D, Berardinelli A, et al. North star ambulatory assessment, 6-minute walk test and timed items in ambulant boys with duchenne muscular dystrophy. Neuromuscul Disord, 2010;20:712-716. https://doi.org/10.1016/j.nmd.2010.06.014

19. Scott E, Eagle M, Mayhew A, et al. Development of a functional assessment scale for ambulatory boys with duchenne muscular dystrophy. Physiother Res Int 2012;17:101-109. https://doi.org/10.1002/pri.520

20. Schober P, Boer C, Schwarte LA. Correlation coefficients: appropriate use and interpretation. Anesth Analg 2018;126:1763-1768. https://doi.org/10.1213/ ANE. 0000000000002864

21. Hayran M. Sağlık araştırmaları için temel istatistik. 1. Baskı. Ankara: Omega Araştırma, 2011;95-108.

22. Mendell JR, Nathalie Goemans N, Lowes LP, et al. Longitudinal effect of eteplirsen versus historical control on ambulation in duchenne muscular dystrophy. Ann Neurol 2016;79:257-271. https://doi.org/10.1002/ ana. 24555

23. De Bruin $M$, Smeulders $M$, Kreulen $M$. Why is joint range of motion limited in patients with cerebral palsy? J Hand Surg (Eur Vol) 2013;38:8-13. https://doi. org/10.1177/1753193412444401 
24. Czaprowski D, Kędra A, Pawłowska P, Kolwicz GańkoA, Leszczewska J, Tyrakowski M. The examination of the musculoskeletal system based only on the evaluation of pelvic-hip complex muscle and trunk flexibility may lead to failure to screen children for generalized joint hypermobility. PloS One 2015;10:e0121360. https:// doi.org/10.1371/journal.pone.0121360

25. Henderson G, Barnes CA, Portas MD. Factors associated with increased propensity for hamstring injury in english premier league soccer players. J Sci Med Sport 2010;13:397-402. https://doi.org/10.1016/j. jsams.2009.08.003

26. Choi YA, Chun SM, Kim Y, Shin HI, et al. Lower extremity joint contracture according to ambulatory status in children with duchenne muscular dystrophy. BMC Musculoskelet Disord 2018;19:287. https://doi. org/10.1186/s12891-018-2212-6

Etik kurul onayı: Çalışma, Hacettepe Üniversitesi Girişimsel Olmayan Klinik Araştırmalar Etik Kurulu tarafından 06.12.2016 tarih ve GO/16740 numarası ile onaylandı.

\section{Yazarların makaleye olan katkıları}

L.A. ve Ö.Y. çalışmanın ana fikrini ve hipotezini kurgulamışlardır. L.A., G.A.Y. ve N.B. teoriyi geliştirmiş, gereç ve yöntem bölümünü düzenlemişlerdir. Sonuçlar kısmındaki verilerin değerlendirmesini I.A.B., A.K. ve Ö.Y. yapmışlardır. Makalenin tartışma bölümü L.A., G.A.Y. ve Ö.Y. tarafından yazıımış, N.B. ve I.A.G. gözden geçirip gerekli düzeltmeleri yapmış ve onaylamıştır. Ayrıca tüm yazarlar çalışmanın tamamını tartışmış ve son halini onaylamıştır. 